\title{
Influence of Cutting Parameters and Tool Wear on the Surface Integrity of Cobalt-Based Stellite 6 Alloy When Machined Under a Dry Cutting Environment
}

\author{
Ge Yingfei, Patricia Muñoz de Escalona, and Alexander Galloway
}

\author{
(Submitted June 8, 2016; in revised form September 27, 2016; published online November 28, 2016)
}

\begin{abstract}
The efficiency of a machining process can be measured by evaluating the quality of the machined surface and the tool wear rate. The research reported herein is mainly focused on the effect of cutting parameters and tool wear on the machined surface defects, surface roughness, deformation layer and residual stresses when dry milling Stellite 6, deposited by overlay on a carbon steel surface. The results showed that under the selected cutting conditions, abrasion, diffusion, peeling, chipping and breakage were the main tool wear mechanisms presented. Also the feed rate was the primary factor affecting the tool wear with an influence of $83 \%$. With regard to the influence of cutting parameters on the surface roughness, the primary factors were feed rate and cutting speed with 57 and $38 \%$, respectively. In addition, in general, as tool wear increased, the surface roughness increased and the deformation layer was found to be influenced more by the cutting parameters rather than the tool wear. Compressive residual stresses were observed in the un-machined surface, and when machining longer than $5 \mathrm{~min}$, residual stress changed $100 \%$ from compression to tension. Finally, results showed that micro-crack initiation was the main mechanism for chip formation.
\end{abstract}

Keywords cobalt-based alloy, deformation layer, machining, residual stress, surface roughness, tool wear

\section{Introduction}

Cobalt-based alloys, also named "Stellite," have a wide range of applications due to their higher melting temperature, superior thermal fatigue resistance, weldability, high-temperature corrosion and oxidation resistance, and wear resistance. Some of the applications are in jet engine, turbines, space vehicles, rocket motors, nuclear reactors, power plants and chemical equipment, electronics and medical devices (Ref 1,2).

One way to increase the product life of components subjected to aggressive environments (i.e., erosive wear) involves the deposition of a surface layer of Stellite on a steel substrate. This process can be conducted by fusion welding techniques such as gas tungsten arc welding (GTAW), gas metal arc welding (GMAW) and plasma transferred arc (PTA) (Ref 3 ). As these surface engineering processes only partially fulfill the demands for tolerances and surface quality, a finishing process to smooth the surface is essential, where in this case electro-discharged machining (EDM) or conventional grinding process is often used. For more complex geometries, the high-speed machining (HSM) method tends to be the preferred option due to economic factors (e.g., absence of electrodes and burning time) (Ref 4).

Ge Yingfei, School of Mechanical Engineering, Nanjing Institute of Technology, Nanjing 211167, China; Patricia Muñoz de Escalona, School of Engineering and Computing, University of the West of Scotland, Paisley PA1 2BE, UK; and Alexander Galloway, Department of Mechanical and Aerospace, University of Strathclyde, Glasgow G1 1XJ, UK. Contact e-mail: p.munoz@uws.ac.uk.
Milling experiments on cast Stellite 12 showed that CBN tools are suitable as a cutting tool material as it combines high hardness, relatively high toughness and chemical stability (Ref 4). Inserts made of $\mathrm{SiC}$-whisker-reinforced ceramics and tungsten carbides proved to be inappropriate for milling at high cutting speeds. Only inserts with a metal binder phase and a high percentage of CBN were convincing because of their better performance regarding tool life. It was also shown that the size, the type and the composition of the carbide phases and the percentage of martensite in the steel had a great effect on the tool's life and its performance (Ref 5). The mechanisms most commonly used to explain the wear of carbide and PCBN tools included abrasion, adhesion, diffusion and chemical wear (Ref 6).

Bagci et al. (Ref 7) studied the milling surface roughness of Stellite 6 cobalt-based alloy using PVD TiN-coated carbide tools, and Benghersallah et al. (Ref 8) examined the dry milling machinability of Stellite 6 alloy layers using tools with five different multilayer coatings. Both groups found that when using a cutting speed between 120 and $230 \mathrm{~m} / \mathrm{min}$, a radial depth of cut of $3 \mathrm{~mm}$, an axial depth of cut of 0.3 and $0.067 \mathrm{~mm} /$ tooth for the feed, the tool life was in general within $2 \mathrm{~min}$ when considering a maximum wear of $\mathrm{VB}=0.3 \mathrm{~mm}$ as the tool life criterion. It was also found that chipping, notching and cracking took place during the course of the tool wear. These researchers also concluded that the AlTiN nanocrystalline coating was the most efficient when using high-speed $(190 \mathrm{~m} / \mathrm{min})$ and dry cutting conditions.

The effect of milling parameters on the tool wear of physical vapor deposition TiN/TiCN/TiAlC coated and uncoated inserts was examined by Aykut et al. (Ref 9). The results showed that the end of the tool life was caused more frequently by chipping, cracking and breakage of the edge (rather than regular tool wear) when compared with the turning and drilling processes.

Ozturk et al. (Ref 10) examined the machinability of Stellite 6 coating material when using a turning process and whisker- 
Table 1 Composition (weight \%) of Stellite 6 alloy (Ref 4)

\begin{tabular}{lllllll}
\hline Co & Cr & W & C & Fe & Mn & \\
\hline 53.35 & 26.65 & 5.07 & 5.86 & 7.05 & 0.92 & 1.09 \\
\hline
\end{tabular}

Table 2 Physical and mechanical properties of Stellite 6 alloy

\begin{tabular}{lccccc}
\hline Hardness, $\mathbf{H V}$ & Density, $\mathbf{g} / \mathbf{c m}^{\mathbf{3}}$ & $\begin{array}{c}\text { Yield strength, } \\
\mathbf{M P a}\end{array}$ & $\begin{array}{c}\text { Ultimate tensile } \\
\text { strength, MPa }\end{array}$ & $\begin{array}{c}\text { Poisson's } \\
\text { ratio }\end{array}$ & $\begin{array}{c}\text { Young's } \\
\text { modulus, GPa }\end{array}$ \\
\hline $400-750 \mathrm{HV}$ (a) & 8.46 & 934 & 1205 & 0.29 & 230 \\
temperature, ${ }^{\circ} \mathbf{C}$
\end{tabular}

At room temperature (Ref 9)

(a) See Fig. 4 for explanation

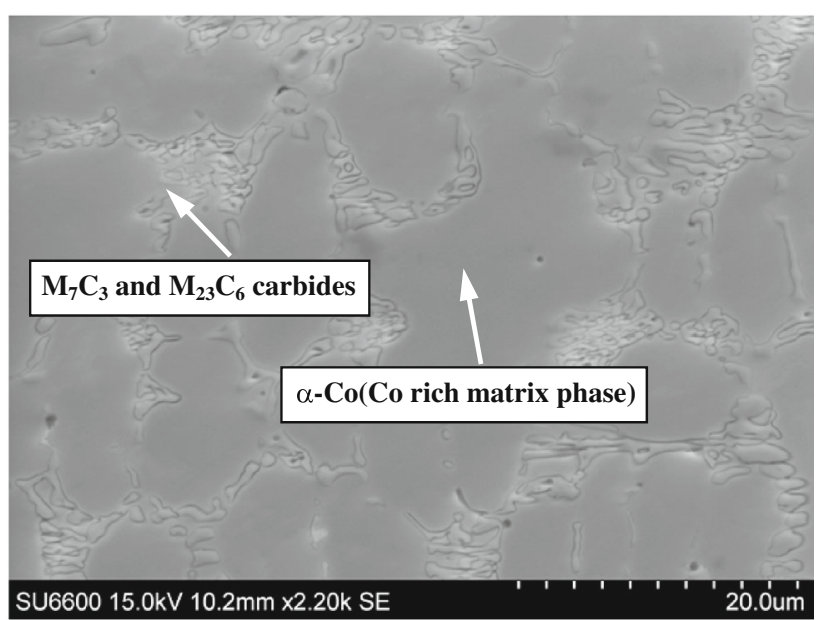

Fig. 1 Microstructure of Stellite 6 cross-sectional area

Table 3 Cutting parameters and their levels selected for the study

\begin{tabular}{lllccc}
\hline Symbol & Cutting parameter & Unit & Level 1 & Level 2 & Level 3 \\
\hline A & Cutting speed, $V$ & $\mathrm{~m} / \mathrm{min}$ & 20 & 30 & 40 \\
$\mathrm{~B}$ & Feed rate, $F$ & $\mathrm{~mm} / \mathrm{min}$ & 25 & 75 & 150 \\
C & Axial depth of cut, $a_{p}$ & $\mathrm{~mm}$ & 0.5 & 1.0 & 1.5 \\
\hline
\end{tabular}

Table $4 \quad L_{9}$ Taguchi orthogonal array

\begin{tabular}{lccc}
\hline Trial & $\boldsymbol{V}, \mathbf{m} / \mathbf{m i n}$ & $\boldsymbol{F}, \mathbf{~ m m} / \mathbf{m i n}$ & $\boldsymbol{a}_{\boldsymbol{p}}, \mathbf{m m}$ \\
\hline 1 & 20 & 25 & 0.5 \\
2 & 20 & 75 & 1.0 \\
3 & 20 & 150 & 1.5 \\
4 & 30 & 25 & 1.5 \\
5 & 30 & 75 & 0.5 \\
6 & 30 & 150 & 1.0 \\
7 & 40 & 25 & 1.0 \\
8 & 40 & 75 & 1.5 \\
9 & 40 & 150 & 0.5 \\
\hline
\end{tabular}

reinforced ceramics and tungsten carbide as cutting tools. The results showed that the quality of the machined surface when using a whisker-reinforced ceramic insert was much better when compared with the results obtained when using a tungsten carbide tool. It was also reported that a surface roughness of 1.8-5.1 $\mu \mathrm{m}$ could be acquired when using a whisker-reinforced ceramic cutting tool under the optimal combination of cutting parameters $(50 \mathrm{~m} / \mathrm{min}, 0.1 \mathrm{~mm} / \mathrm{rev}$ and a depth of cut of $0.25 \mathrm{~mm})$.

An investigation on the milling of cast and deposited Stellite 12 with different milling tools was carried out by Danny et al. (Ref 4). The results showed that the highest value of tool life was reached when using cutting speeds of $150 \mathrm{~m} / \mathrm{min}$ or higher, especially when using CBN tools with double negative angles. Also a bigger tool life was obtained when milling cast Stellite when compared with PTA-welded Stellite. The authors attributed this result to the differences in the microstructures between the cast and the PTA-welded material. The results also showed that the depth of the hardening zone was $0.14 \mathrm{~mm}$, and the top layer showed a rise in hardness of up to $700 \mathrm{HV}_{5}$ and partially even up to $750 \mathrm{HV}_{5}$. This increase in hardness caused outbreaks of the cutting edge and had an extremely negative effect on tool life. Finally, it was concluded that milling of Stellite 12 with CBN under high-speed cutting conditions is possible.

Finally, Shao et al. (Ref 11) investigated the machinability of Stellite 12 alloys during a turning process when using uncoated carbide tools under the dry cutting condition. The results showed that TiAlN-coated carbide tools in general demonstrated a good machining performance at low levels of cutting speed and loads; however, it is not recommended for relatively heavy cutting loads; also built-up-edge formation was found under some cutting conditions, that excessive tool flank typically resulted in tool breakage at the cutting edge of the uncoated tools and also that at low cutting speeds, abrasive and adhesive wear were often observed while diffusion, chipping and chemical wear occurred at higher cutting speeds.

Most of the aforementioned researchers have focused their studies on the machinability of wrought or cast Stellite 12 alloys using coated and/or uncoated carbide tools where the investigations were mainly focused toward the analysis of the tool life and tool wear for turning processes. In order to fill the knowledge gap related to the milling of Stellite 6 coatings, a novel study related to chip formation mechanism has been undertaken as well as a study relating the influence of cutting parameters and tool wear on the quality of the machined surface to establish the optimal parameters for the efficient and economic machining of this alloy. 


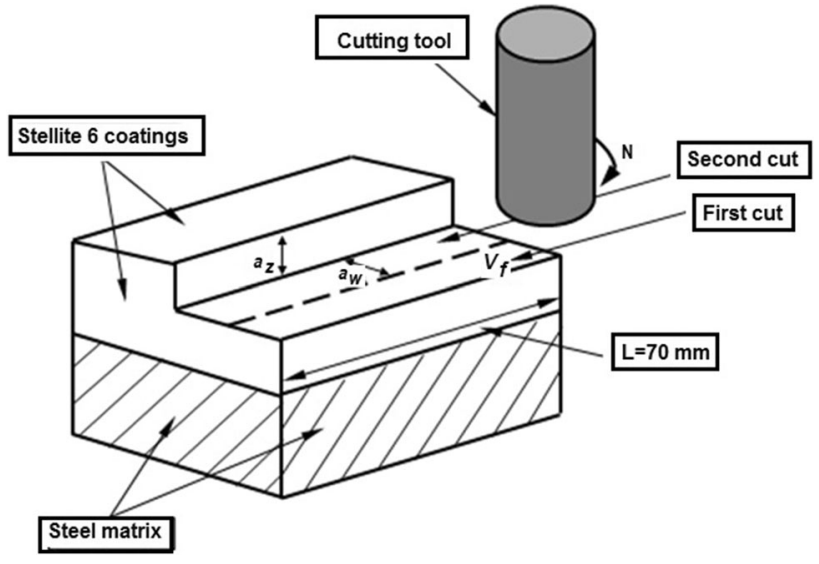

Fig. 2 Schematic drawing of the cutting process

\section{Materials and Experimental Setup}

\subsection{Workpiece}

Samples of carbon steel with dimensions of $70 \times 40 \times 15 \mathrm{~mm}$ coated with a multiple layer of Stellite 6 , with a thickness of $6 \mathrm{~mm}$, were selected for the experiment. The Stellite multiple layers were deposited by the gas tungsten arc welding (GTAW) technique. The composition and physical and mechanical properties of this Stellite 6 alloy coating are given in Tables 1 and 2, respectively. Figure 1 shows the microstructure of the Stellite 6 coating.

\subsection{Cutting Tool}

A HERTEL ${ }^{\mathrm{TM}}$ 16-mm-diameter TiAIN carbide-coated end mill with 4 flutes and a tool rake angle of $8^{\circ}$, tool nose radius

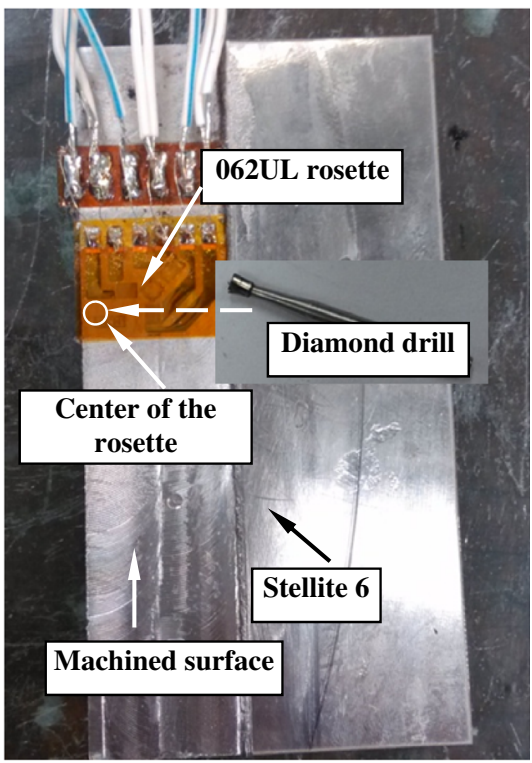

(a)

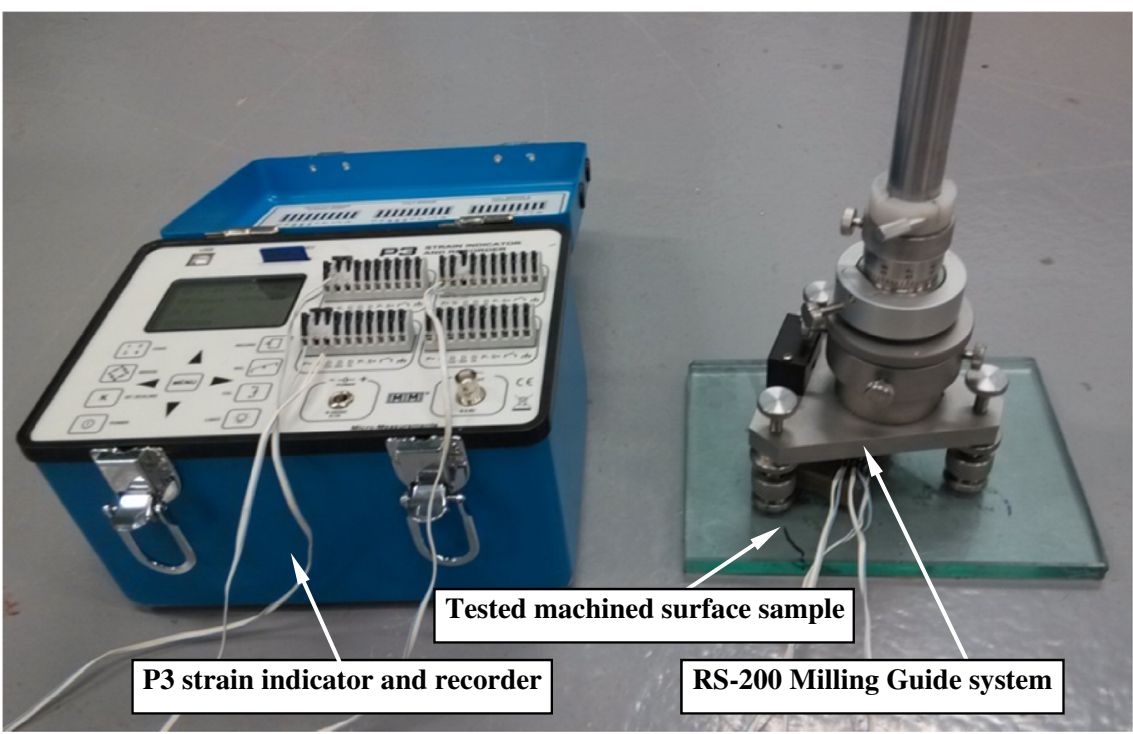

(b)

Fig. 3 Detail of the equipment used for the residual stresses measurements. (a) Location of the strain gauge (rosette) on the machined surface, (b) the RS-200 Milling Guide residual stresses measurements system 

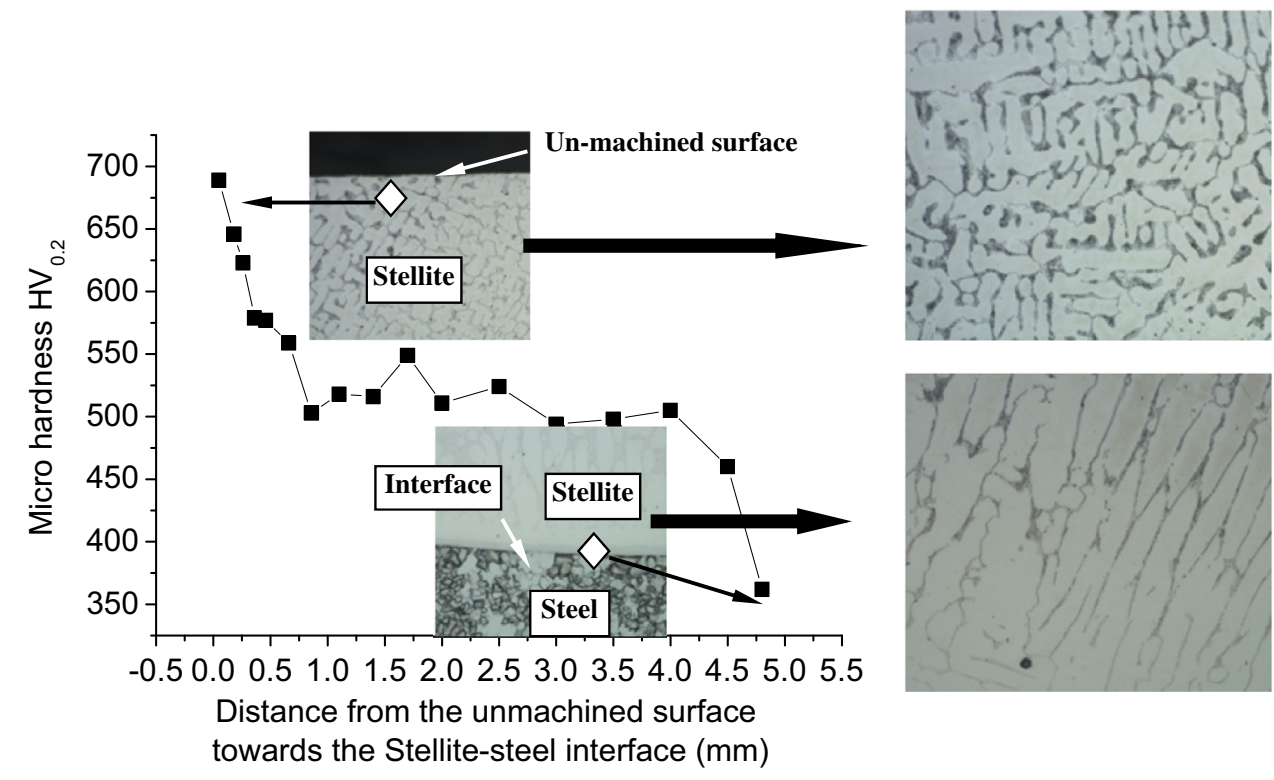

Distance from the unmachined surface

Fig. 4 Micro-hardness profile of Stellite 6 layer's cross-sectional area
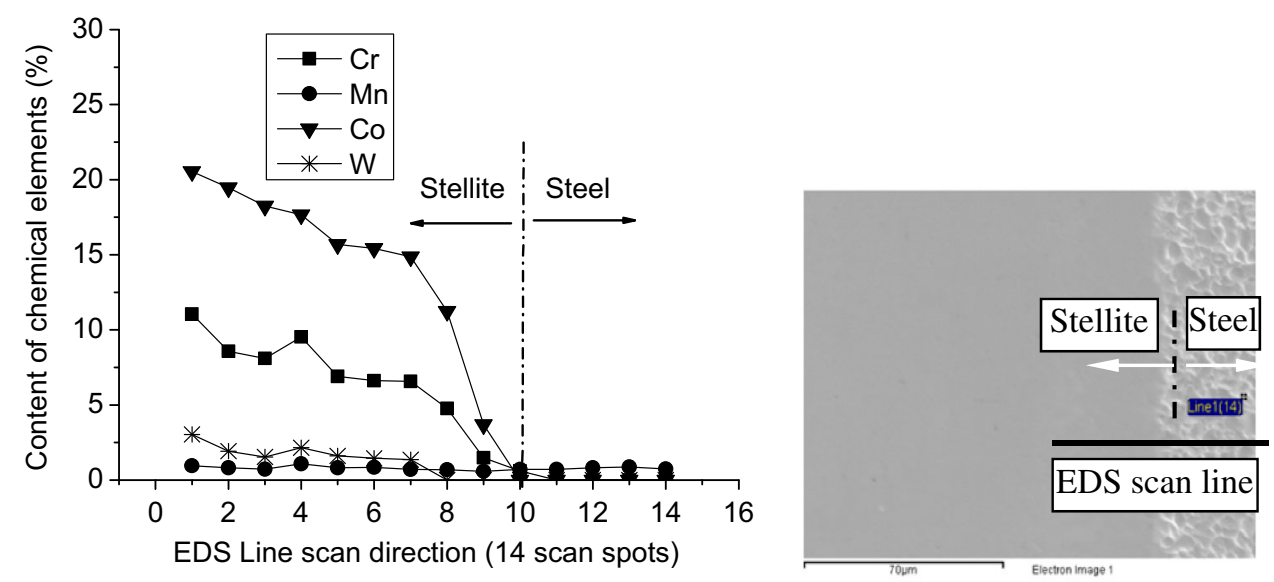

Fig. 5 EDS analysis along the cross-sectional area of the sample near the Stellite-steel interface

Table 5 Experimental results for tool wear and corresponding $\mathrm{S} / \mathrm{N}$ ratio

\begin{tabular}{lcccccccrr}
\hline Trial & $\mathbf{1}$ & $\mathbf{2}$ & $\mathbf{3}$ & $\mathbf{4}$ & $\mathbf{5}$ & $\mathbf{6}$ & $\mathbf{7}$ & $\mathbf{8}$ & $\mathbf{9}$ \\
\hline $\mathrm{VB}_{\max }, \mathrm{mm}$ & 0.58 & 0.69 & 2.31 & 0.53 & 0.67 & 1.41 & 0.46 & 0.66 & 1.01 \\
$\mathrm{~S} / \mathrm{N}$ ratio, $\mathrm{dB}$ & 4.74 & 3.15 & -7.27 & 5.51 & 3.39 & -3.0 & 6.63 & 3.63 & -0.097 \\
\hline
\end{tabular}

Table 6 Mean $\mathrm{S} / \mathrm{N}$ response table for tool wear $\mathrm{VB}_{\max }$

\begin{tabular}{|c|c|c|c|c|c|}
\hline \multirow[b]{2}{*}{ Symbol } & \multirow[b]{2}{*}{ Cutting parameters } & \multicolumn{4}{|c|}{ Mean $S / N$ ratio $(\mathrm{dB})$} \\
\hline & & Level 1 & Level 2 & Level 3 & Max-Min \\
\hline A & Cutting speed & 0.21 & 1.97 & 3.39 & 3.18 \\
\hline B & Feed rate & 5.62 & 3.39 & -3.45 & 9.08 \\
\hline $\mathrm{C}$ & Axial depth of cut & 2.68 & 2.26 & 0.62 & 2.05 \\
\hline
\end{tabular}


$0.3 \mathrm{~mm}$, clearance $10^{\circ}$ and helix angle of $10^{\circ}$ was selected for the experiments. This tool was selected due to its performance in previous research (Ref 11).

\subsection{Experimental Setup}

The Taguchi method was used as the design of experiments. A $L_{9}\left(3^{3}\right)$ orthogonal array was selected which corresponds to 3 parameters with 3 levels each as shown in Table 3. Table 4 shows the combination of cutting parameters for each of the trials. The values of the cutting parameters were recommended by the tool supplier based on the tool-workpiece hardness combination. The radial depth of cut was kept constant at $8 \mathrm{~mm}$. The analysis of variance (ANOVA) was applied to obtain each cutting parameter's contribution on the tool wear and the surface roughness. A Beavermill MK2 NC milling machine was selected to conduct the down-milling experiments under a dry cutting condition. It must be highlighted that a new tool was used for each of the trials.

\subsection{Surface Roughness and Tool Wear Measurements}

Once the machining process was concluded, the surface roughness was measured across the tool feed direction using a Mitutoyo Surftest SV-2000 equipment following the ASME B46.1 standard (Ref 12). The cutoff length was set at $17.5 \mathrm{~mm}$ which included 5 readings. The roughness was measured after cutting the first $140 \mathrm{~mm}$. Figure 2 shows a schematic drawing of the cutting process.

The flank wear $\mathrm{VB}_{\max }$ was measured using a Mitutoyo vision measuring machine following the ISO 8688-2:1989

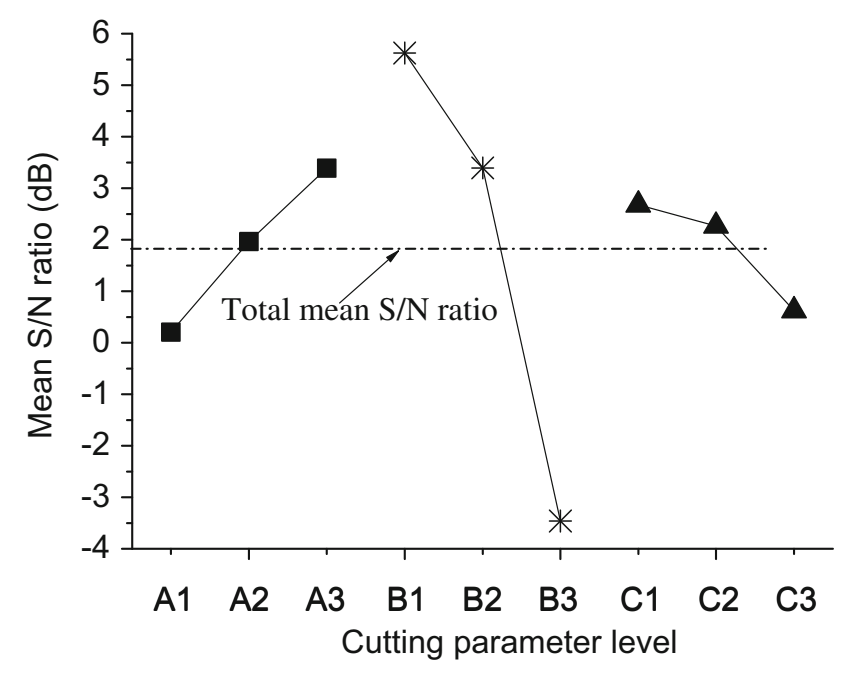

Fig. 6 Mean S/N response graph for tool wear standard (Ref 13). Each cutting flute was marked and measured, and an average was reported. SEM and EDS were used for tool wear analysis. To aid the level of accuracy, the surface roughness and tool wear were measured twice during the cutting process. The first measurement was taken after cutting the first $140 \mathrm{~mm}$, which consisted of a $16 \mathrm{~mm}$ width (2 passes of $8 \mathrm{~mm}$ in radial depth of cut) with a length of $70 \mathrm{~mm}$. The second measurement was taken at the end of the cutting process (cutting length $L=400 \mathrm{~mm}$ ). Tool wear land was examined on the Olympus GX51 metallurgical microscope and scanning electron microscope (SEM, Hitachi S-3700N and SU 6600).

\subsection{Metallographic Analysis}

Metallographic preparation for workpiece, tool and deformed layer samples was conducted following the ISO 4499-2 standard (Ref 14), and the etching of the samples was conducted following the ISO 21608 standard (Ref 15). Hardness tests were performed based on the ISO 6507-1 standard (Ref 16) using a Mitutoyo MVK-G1 hardness-testing unit at a load of $200 \mathrm{~g}$ and a 15-s delay.

\subsection{Residual Stress Measurements}

Residual stresses were measured before and after the machining process using the incremental hole-drilling technique (Ref 17, 18) and following ASTM E837-08 standard (Ref 19). In this case, a 062UL strain gauge rosette (three grids) was selected. Measurements were recorded every $0.1 \mathrm{~mm}$ in depth until reaching a maximum depth of $1 \mathrm{~mm}$ from the machined surface. Hole-Drilling Residual Stresses Calculation Program (version 3.21) software was used to convert the strain values into residual stress values. It must be highlighted that the residual stresses were measured twice in each trial: The first measurement was taken on the un-machined surface (as received condition) and the second measurement after the milling process was concluded. A Milling Guide system Model RS-200 was used to drill the hole at the center of the strain gauge (see Fig. 3).

\subsection{Analysis of Chips and Deformed Machine Layer}

After completing the milling process under the combination of cutting parameters specified in Table 4, samples of chips were collected in order to analyze the chip formation mechanisms. For this analysis, a metallographic preparation was conducted following the ISO 4499-2 standard (Ref 14) and the etching of the samples was conducted following the ISO 21608 standard (Ref 15). An Olympus GX51 metallurgical microscope and scanning electron microscope (SEM, Hitachi S-3700N and SU 6600) were used to collect the images. The same standards and image analysis were used for the machined deformed layer study.

Table 7 ANOVA data for the tool wear

\begin{tabular}{lcccccc}
\hline Factor & Degrees of freedom & Sum of squares (SDQ) & Variance & Test $\boldsymbol{F}$ & $\boldsymbol{F}, \mathbf{5 \%}$ & Percentage of contribution \\
\hline A $(V, \mathrm{~mm} / \mathrm{min})$ & 2 & 15.24 & 7.62 & 2.69 & 19 & 9.38 \\
B $(F, \mathrm{~mm} / \mathrm{min})$ & 2 & 134.40 & 67.2 & 23.78 & 19 & 82.77 \\
C $\left(a_{p}, \mathrm{~mm}\right)$ & 2 & 7.08 & 3.54 & 1.25 & 19 & 4.37 \\
Error & 2 & 5.65 & 2.82 & & 3.48 \\
Total & 8 & 162.37 & 81.18 & & 100 \\
\hline
\end{tabular}




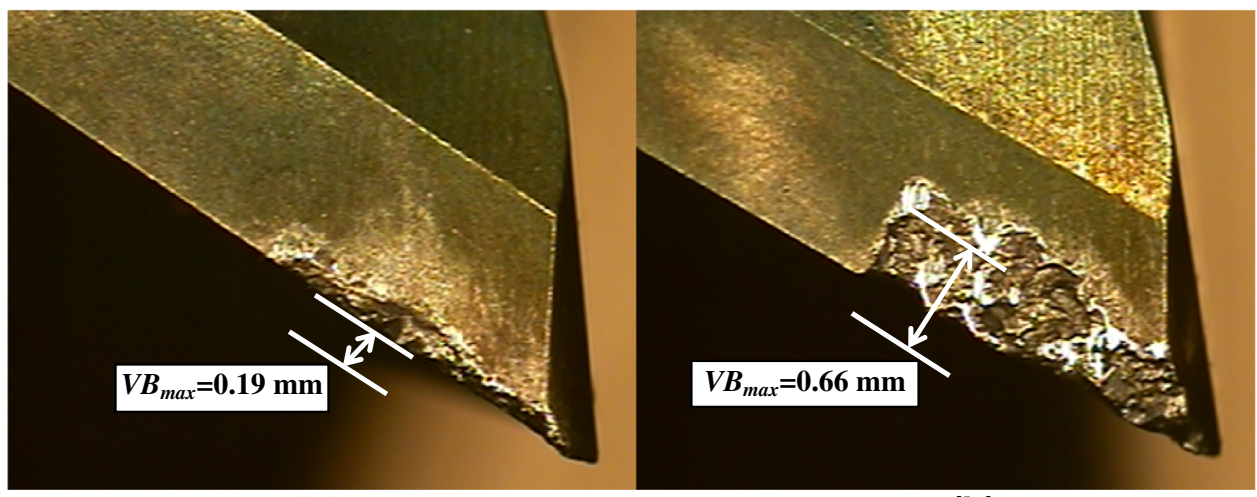

(a)

(b)

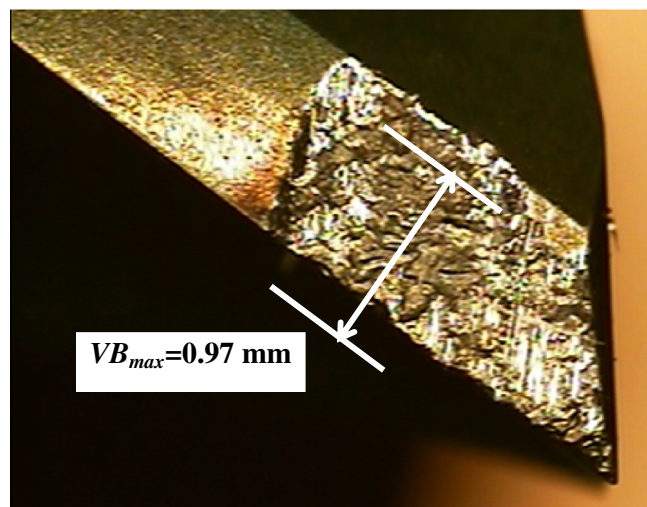

(c)

Fig. 7 Tool wear appearance for different cutting length/time when cutting at $30 \mathrm{~m} / \mathrm{min}, 25 \mathrm{~mm} / \mathrm{min}$ and $1.5 \mathrm{~mm}$ of axial depth of cut (Trial 4). (a) $\mathrm{L}=70 \mathrm{~mm}(2.8 \mathrm{~min})$, (b) $\mathrm{L}=140 \mathrm{~mm}(5.6 \mathrm{~min})$ and (c) $\mathrm{L}=400 \mathrm{~mm}(16 \mathrm{~min})$

\section{Results and Discussion}

Figure 4 shows the micro-hardness profile of the Stellite 6 cross-sectional area. When analyzing Fig. 4, it is observed that the highest value of hardness is located at the surface of the coated layer of Stellite 6 where the value of hardness reached $690 \mathrm{HV}_{0.2}$ decreasing gradually to $360 \mathrm{HV}_{0.2}$ toward the Stellite-steel interface. This significant decrease in hardness near the interface is due to the change in microstructure and chemical composition as a consequence of the chemical metallurgy effect during the welding process for the development of the Stellite coating. As can be observed in Fig. 4, the grain size of the cobalt matrix near the interface is much coarser than that in the un-machined surface. On the other hand, the number of carbides near the interface is significantly less than in the un-machined surface. Figure 5 also shows that the content of $\mathrm{Co}, \mathrm{Cr}, \mathrm{Mn}$ and $\mathrm{W}$ decreases from the un-machined surface toward the Stellite-steel interface.

\subsection{Influence of Cutting Parameters on Tool Wear}

3.1.1 $S / N$ Ratio for Tool Wear. To obtain the optimal combination of cutting parameter that guarantees a small tool wear (which is reflected on a longer tool life) and small value of roughness, when machining Stellite 6 , the $S / N$ ratio was calculated based on the smaller-the-better characteristic, as shown in Eq 1:
$\frac{S}{N}=-10 \log _{10}\left(\frac{1}{n} \sum_{i=1}^{n} y_{i}^{2}\right)$

where $y_{i}$ is the observed data and $n$ is the number of observations.

Table 5 shows the experimental results for tool wear $\mathrm{VB}_{\max }$ and the corresponding $S / N$ ratio for each trial. The mean $S / N$ response value and $S / N$ response graph for each level of parameter are shown in Table 6 and Fig. 6. When analyzing Fig. 6, it is observed that factor B (feed rate) has the highest difference between maximum and minimum values (9.08) and as a consequence of the major impact on the tool wear, followed by factor A (cutting speed) and factor C (axial depth of cut) with values of 3.18 and 2.05 , respectively. Also, in general it is observed that tool wear increases when feed rate and axial depth of cut are increased and the cutting speed is decreased.

Figure 6 also shows when analyzing the $S / N$ ratio that the optimal combination of cutting parameters to achieve a small tool wear (longer tool life) is obtained when using level 3 of factor A (cutting speed), level 1 of factor B (feed rate) and level 1 of factor $\mathrm{C}$ (axial depth of cut). Consequently, the optimum cutting conditions for a small tool wear are $40 \mathrm{~m} / \mathrm{min}, 25 \mathrm{~mm} /$ min and $0.5 \mathrm{~mm}$ for the axial depth of cut. This value of $40 \mathrm{~m} /$ $\min$ is $75-100 \%$ higher than the value reported by previous researcher (Ref 20), representing savings in costs as machining time decreases when increasing the cutting speed. 


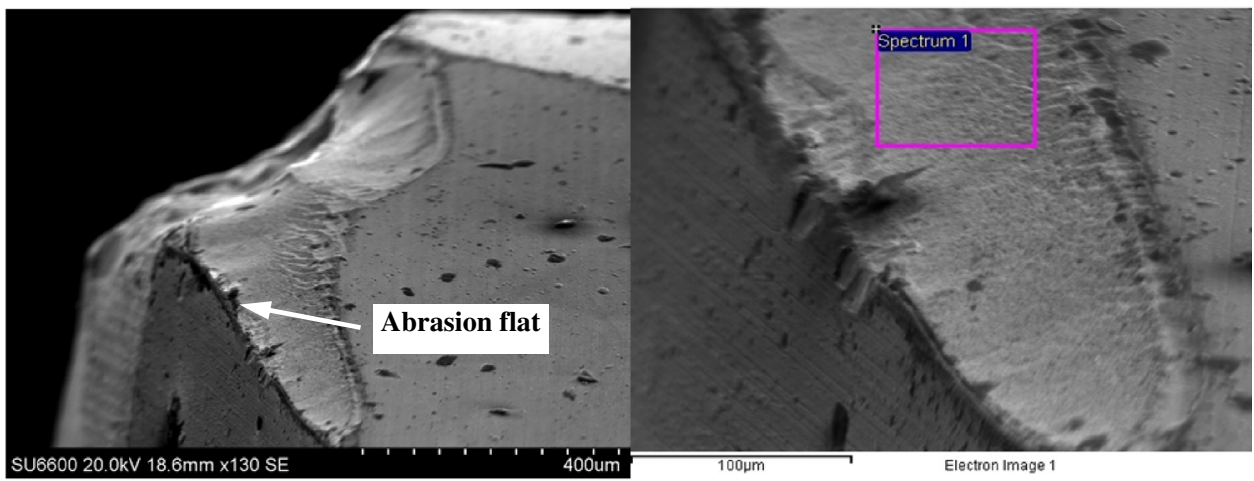

(a)

(b)

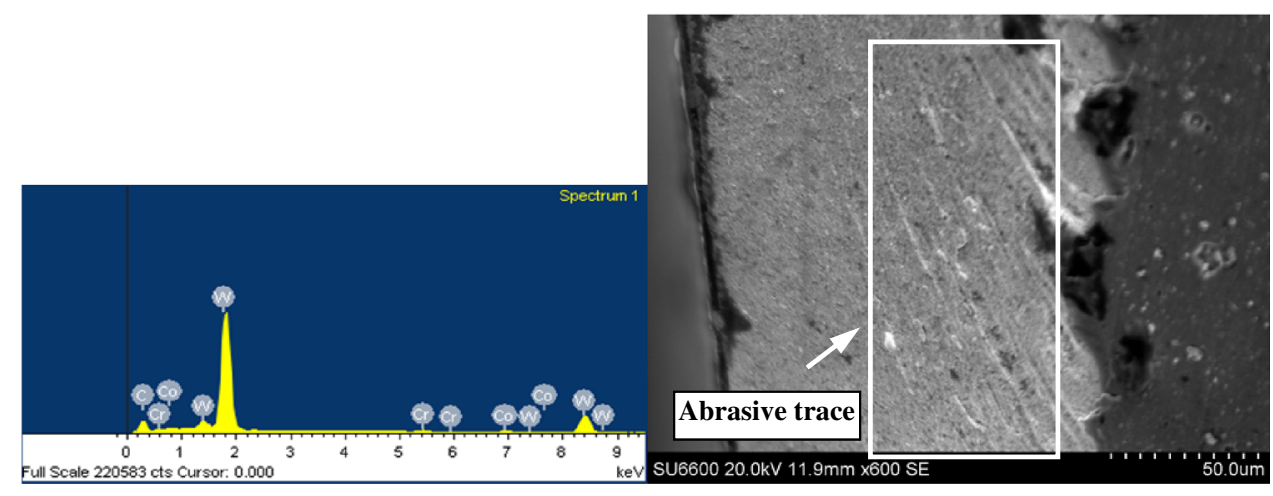

(c)

(d)

Fig. 8 Abrasion mechanism presented on the tool nose and detail of the diffusion mechanism (after etched) for Trial $4(30 \mathrm{~m} / \mathrm{min}, 25 \mathrm{~mm} / \mathrm{min}$ and $1.5 \mathrm{~mm}$ of axial depth of cut). (a) Tool's nose $(\mathrm{t}<2.8 \mathrm{~min}$ ), (b) detail of tool's nose area where abrasion mechanism was present, (c) EDS for (b) and (d) cutting edge (flank)

Table 8 Comparison of the chemical elements present in the tool wear land and the new tool matrix

\begin{tabular}{lccc}
\hline Element, wt.\% & Tool wear land & Tool matrix & Diffusion \\
\hline $\mathrm{C}$ & 13.52 & 7.65 & From Stellite to tool \\
$\mathrm{Cr}$ & 2.13 & 0.56 & From Stellite to tool \\
$\mathrm{Co}$ & 4.75 & 8.41 & From tool to Stellite \\
$\mathrm{W}$ & 79.60 & 83.38 & From tool to Stellite \\
\hline
\end{tabular}

Table 9 Chemical composition (wt.\%) for the inclusion shown in Fig. 10(b)

\begin{tabular}{ccccccccccc}
\hline $\mathbf{C}$ & $\mathbf{O}$ & $\mathbf{N a}$ & Al & $\mathbf{S i}$ & $\mathbf{K}$ & $\mathbf{C a}$ & $\mathbf{T i}$ & $\mathbf{C r}$ & $\mathbf{M n}$ & $\mathbf{F e}$ \\
\hline 3.09 & 40.43 & 0.59 & 12.26 & 20.63 & 15.88 & 0.84 & 0.15 & 2.79 & 0.55 & 0.35 \\
\hline
\end{tabular}

3.1.2 Analysis of Variance for Tool Wear. As previously mentioned, the $S / N$ ratio with a smaller-the-better formula was used to identify the optimal cutting conditions for a small value of tool wear. With ANOVA (Table 7), the percentage of contribution of each cutting parameter on the tool wear $\mathrm{VB}_{\max }$ is almost $83 \%$ for feed rate, followed by the cutting speed and the axial depth of cut with 9 and $4 \%$ of influence, respectively.

\subsection{Tool Wear and the Mechanisms}

Figure 7 shows optical images of tool wear at different stages in the cutting process when using a cutting speed of
$30 \mathrm{~m} / \mathrm{min}$, feed rate of $25 \mathrm{~mm} / \mathrm{min}$ and an axial depth of cut of $1.5 \mathrm{~mm}$. Further results obtained through SEM observations and EDS analysis corroborate that abrasion, coating peeling, cutting edge chipping and breakage were the main tool wear patterns present when milling Stellite 6 alloy under the different cutting conditions. Figure 8 shows these results for Trial 4 ( $30 \mathrm{~m} / \mathrm{min}, 25 \mathrm{~mm} / \mathrm{min}$ and $1.5 \mathrm{~mm}$ as axial depth of cut). As observed, the abrasion mechanisms were developed on the tool's nose and flank edge after cutting for a short period of time $(t<2.8 \mathrm{~min})$, showing a smooth surface appearance (Fig. 8a). This type of tool wear was mainly caused by the 


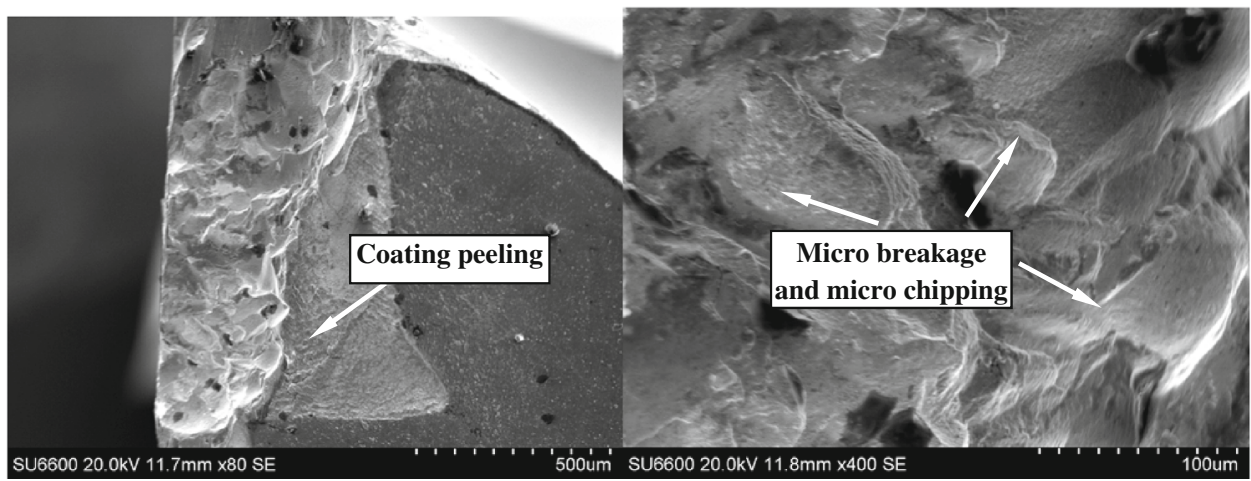

(a)

(b)

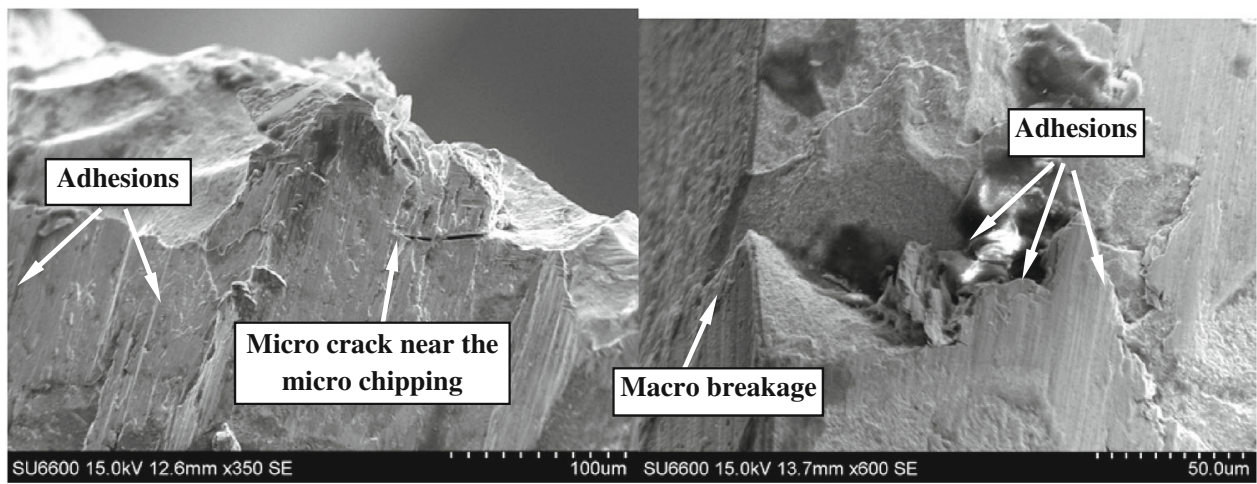

(c)

(d)

Fig. 9 Example of coating peeling, chipping and breakage on the cutting edge and wear land appeared in a cutting tool after $30 \mathrm{~s}$ of cutting. Trial 6 (30 m/min, $150 \mathrm{~mm} / \mathrm{min}, 1.0 \mathrm{~mm})$. (a) Coating peeling, (b) micro-breakage and micro-chipping, (c) crack and (d) macro-breakage

combination effect of the cutting parameters (low value of feed rate) and the chemical elements that diffused between the Stellite 6 coating and the tool. EDS analysis (Fig. 8c) shows the proofs of the presence of the diffusion wear mechanism, where the $\mathrm{C}$ and $\mathrm{Cr}$ elements of the Stellite have diffused into the cutting tool (Fig. 8b) and $\mathrm{Co}$ and $\mathrm{W}$ elements of the tool have diffused into the Stellite (Table 8). Hard carbides (Fig. 1) and inclusions located in the Stellite coating were also responsible for the abrasive mechanism, and this is commented further on in this research (Fig. 10b and Table 9). It must be highlighted that in previous research (Ref 11), a high quantity of Cr element was also observed in the tool wear area, where diffusion wear occurred on the rake and the flank faces of the tool when turning Stellite 12 alloy. Unexpectedly, the proof of the diffusion of $\mathrm{Fe}$ of the workpiece into the tool was not found in this study as well as in Shao's study (Ref 11).

Figure 9 shows results from Trial $6(30 \mathrm{~m} / \mathrm{min}, 150 \mathrm{~mm} /$ $\min , 1.0 \mathrm{~mm}$ ) where the presence of micro-breakage and microchipping wear mechanism was obtained just after $30 \mathrm{~s}$ of cutting, as a consequence of increasing the feed rate $500 \%$ (from 25 to $150 \mathrm{~mm} / \mathrm{min}$ ). These results are compared to results shown in Fig. 8, where no micro-breakage and micro-chipping were found. The micro-breakage or micro-chipping probably produced a macro-breakage (Fig. 9c). There were also insignificant adhesions (Fig. 9d) on the tool wear land; however, it must be highlighted that in general this adhesion mechanism was not present under the values and combination of cutting parameters used in this study.

\subsection{Influence of Cutting Parameters and Tool Wear on Surface Integrity}

As shown in Fig. 10(a), in general, the Stellite matrix near the clusters of the carbides was often torn up during the cutting process. The grooves on the machined surface were formed either by the worn tool or by the presence of carbides in the matrix (Fig. 1 and 10a), and micro-pits remained on the machined surface as a consequence of the carbides being pulled out (Fig. 10a). The protuberances on the machined surface were mainly due to embedment of the chips and the inclusion of carbides in the Stellite coating material. Micro-cracks were formed around the inclusions during the removal process of the matrix (Fig. 10b). Table 9 shows the chemical composition of the inclusion shown in Fig. 10(b). The tool trail and the material plastic deformation (swelling) effect due to the plastic side flow at the tool edge resulted in the obvious marks on the machined surface (Fig. 10c). Another defect on the machined surface was induced by the chatter mechanisms during the cutting process, as shown in Fig. 10(d). Previous research has shown similar behavior when machining cobalt-based alloys (Ref 21).

Figure 11 shows the appearance of the machined surface for three different cutting conditions. When analyzing this figure, it is observed that feed rate and cutting speed both have a significant effect on the machined surface defects. As shown in Fig. 11(a), the machined surface showed a more deteriorated aspect when compared with the machined surface shown in Fig. 11(b), where an increase of $100 \%$ of the cutting speed was 


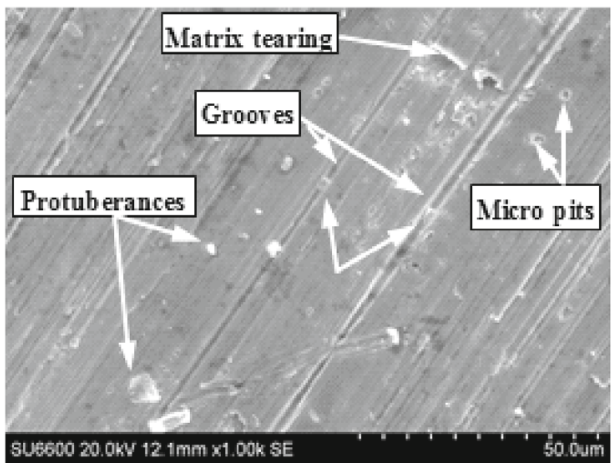

(a)

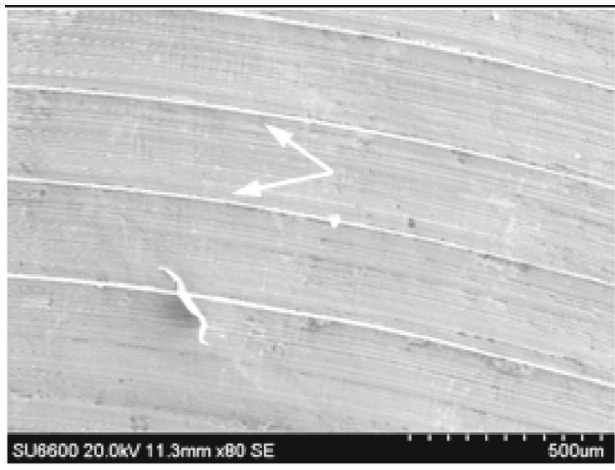

(c)

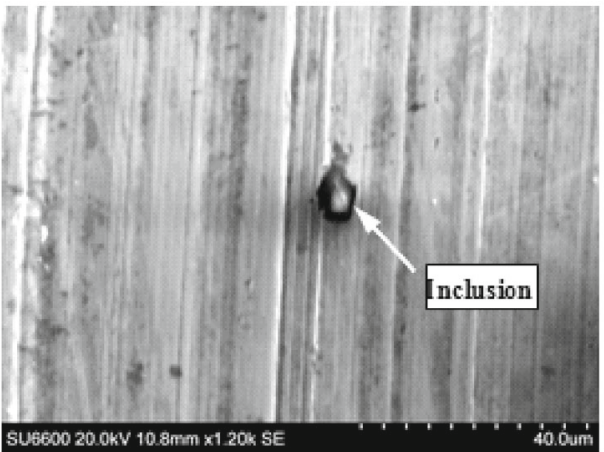

(b)

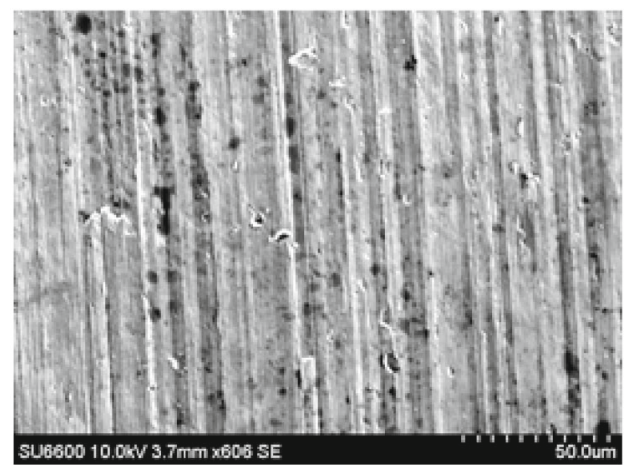

(d)

Fig. 10 Machining induced defects when milling Stellite 6 alloy (a) Matrix tearing, pits, grooves and protuberances, (b) inclusion and microcrack, (c) tool trail and plastic flow marks and (d) cutting chatter marks

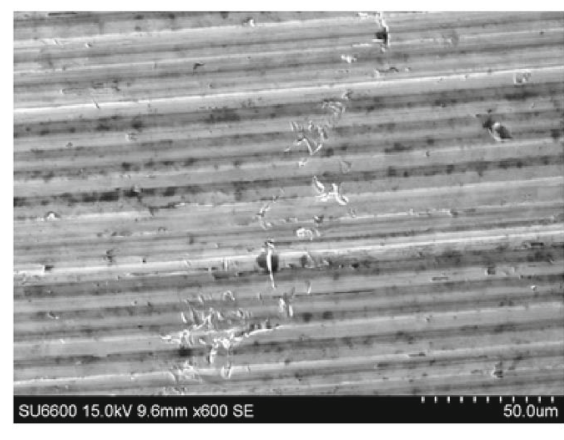

(a)

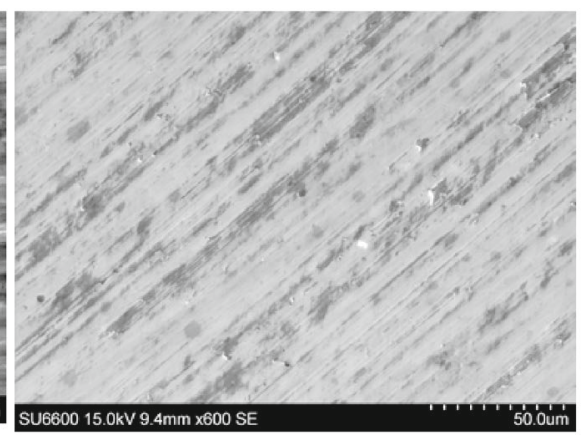

(b)

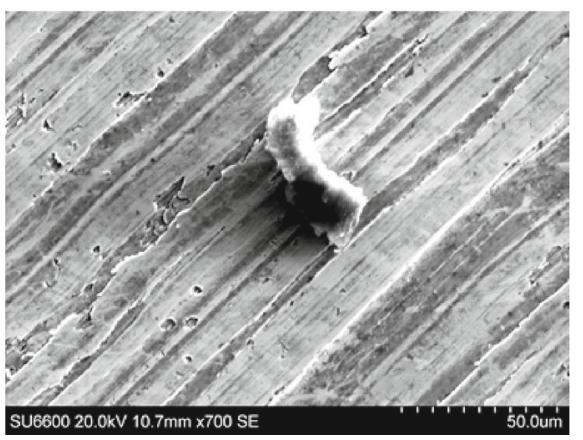

(c)

Fig. 11 Appearance of the machined surface after cutting under different cutting conditions (ap $\leq 1.0 \mathrm{~mm}$ ). (a) $\mathrm{V}=20 \mathrm{~m} / \mathrm{min}, \mathrm{F}=25 \mathrm{~mm} /$ min, (b) $\mathrm{V}=40 \mathrm{~m} / \mathrm{min}, \mathrm{F}=25 \mathrm{~mm} / \mathrm{min}$ and (c) $\mathrm{V}=40 \mathrm{~m} / \mathrm{min}, \mathrm{F}=150 \mathrm{~mm} / \mathrm{min}$

Table 10 Experimental results for surface roughness and $\mathrm{S} / \mathrm{N}$ ratio

\begin{tabular}{|c|c|c|c|c|c|c|c|c|c|}
\hline Trial & 1 & 2 & 3 & 4 & 5 & 6 & 7 & 8 & 9 \\
\hline Surface roughness, $\mu \mathrm{m}$ & 0.88 & 1.13 & 3.31 & 0.39 & 0.80 & 1.67 & 0.35 & 0.59 & 0.83 \\
\hline $\mathrm{S} / \mathrm{N}$ ratio, $\mathrm{dB}$ & 1.06 & -1.08 & -10.39 & 8.07 & 1.93 & -4.44 & 9.04 & 4.59 & 1.61 \\
\hline
\end{tabular}

used (from 20 to $40 \mathrm{~m} / \mathrm{min}$ ). This result is due to the presence of chatter when machining at low cutting speed and feed rate $(20 \mathrm{~m} / \mathrm{min}, 25 \mathrm{~mm} / \mathrm{min})$. When comparing Fig. 11(b) with Fig. 11(c) a, more deteriorated surface is observed when increasing the feed rate $500 \%$ (from 25 to $150 \mathrm{~mm} / \mathrm{min}$ ), in this case, the embedment of the chip on the Stellite coating, and pits were responsible for this result.

3.3.1 Analysis of Signal-to-Noise $(S / N)$ Ratio on the Surface Roughness. Table 10 shows the experimental results for surface roughness and the corresponding $S / N$ ratio for each 


\begin{tabular}{|c|c|c|c|c|c|}
\hline \multirow[b]{2}{*}{ Symbol } & \multirow[b]{2}{*}{ Cutting parameters } & \multicolumn{4}{|c|}{ Mean $S / N$ ratio, dB } \\
\hline & & Level 1 & Level 2 & Level 3 & Max-Min \\
\hline A & Cutting speed & -3.47 & 1.85 & 5.08 & 8.55 \\
\hline B & Feed rate & 6.06 & 1.81 & -4.41 & 10.47 \\
\hline $\mathrm{C}$ & Axial depth of cut & 1.53 & 1.17 & 0.76 & 0.77 \\
\hline
\end{tabular}

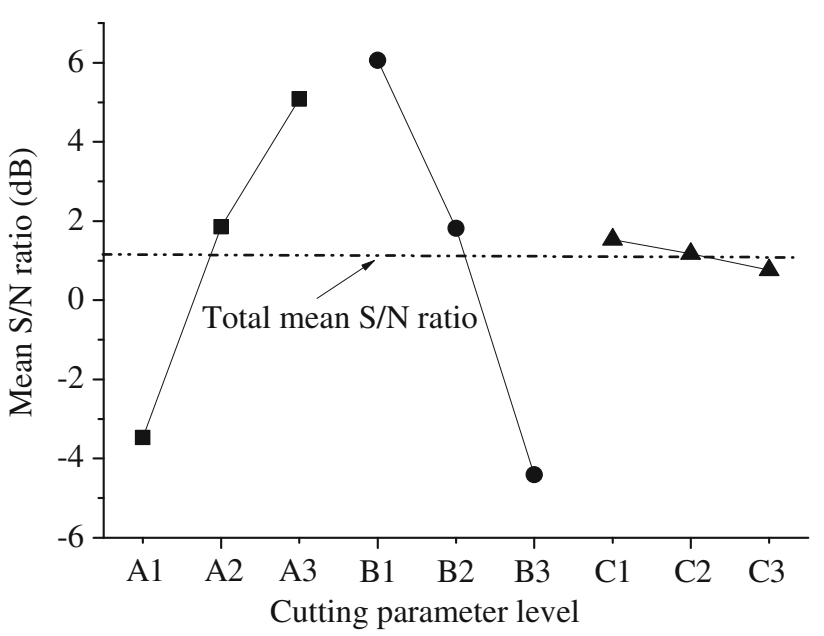

Fig. 12 Mean $\mathrm{S} / \mathrm{N}$ response graph for surface roughness

trial. The mean $S / N$ response value and $S / N$ response graph for each level of parameter are shown in Table 11 and Fig. 12, respectively. As observed in Table 10, Trial 7 had the lowest value of surface roughness and the highest $\mathrm{S} / \mathrm{N}$ ratio, which matches to the smaller-the-better characteristic. According to Table 11 and Fig. 12, factor B (feed rate) has the highest difference between maximum and minimum values (10.47) followed by factor A (cutting speed) and factor C (axial depth of cut) with 8.55 and 0.77 , respectively. Therefore, the feed rate and the cutting speed are the two factors with significant influence on the surface roughness. This result is consistent with previous research (Ref 22).

3.3.2 Analysis of Variance for Surface Roughness. Table 12 shows the ANOVA data for the surface roughness. As observed, the interaction between the $S / N$ and the axial depth of cut does not produce a significant level of contribution $(0.3 \%)$ within the reliability interval of $95 \%$. In other words, axial depth of cut has no effect on $S / N$ ratio. However, a significant correlation between the $S / N$ and the feed rate and the cutting speed was observed. Also, the feed rate has a contribution $57 \%$ and the cutting speed $38 \%$. From Fig. 12, it is observed that level 3 of factor A (cutting speed), level 1 of factor B (feed rate) and level 1 of factor C (axial depth of cut) produced the lowest value of surface roughness when analyzing the $S / N$ ratio. Consequently, the optimum combination of cutting parameters for a low value of roughness is $40 \mathrm{~m} / \mathrm{min}$, $25 \mathrm{~mm} / \mathrm{min}$ and $0.5 \mathrm{~mm}$ for the axial depth of cut. The surface roughness value obtained under these cutting conditions should be less than $0.35 \mu \mathrm{m}$ which belongs to the value obtained for Trial $7(40 \mathrm{~m} / \mathrm{min}, 25 \mathrm{~mm} / \mathrm{min}$ and $1.0 \mathrm{~mm}$ as axial depth of cut). This value of roughness is much lower than the result

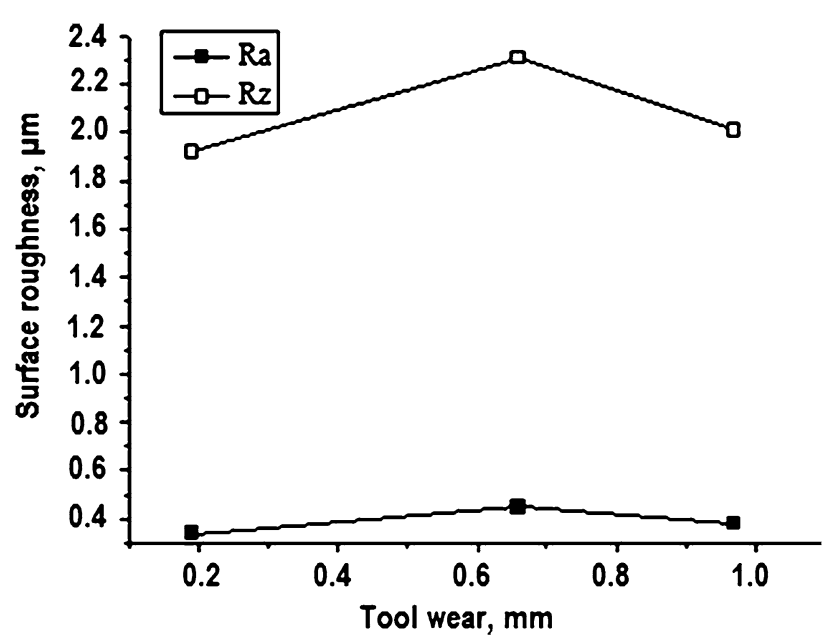

Fig. 13 Effect of tool wear on the machined surface roughness (Trial 4: $30 \mathrm{~m} / \mathrm{min}, 25 \mathrm{~mm} / \mathrm{min}$ and $1.5 \mathrm{~mm}$ as axial depth of cut)

obtained by Ozturk (Ref 10) where a value of 1.8-5.1 $\mu \mathrm{m}$ was achieved when milling submerged arc-welded Stellite 6 coating using $50 \mathrm{~m} / \mathrm{min}, 0.1 \mathrm{~mm} / \mathrm{rev}$ and depth of cut of $0.25 \mathrm{~mm}$ with whisker-reinforced ceramic cutting tool.

\subsection{The Effect of Tool Wear on the Machined Surface and Its Surface Roughness}

The effect of tool wear on the surface roughness is shown in Fig. 13, where it is observed how, in general, the roughness increases when tool wear is increased until the failure criteria $\mathrm{VB}_{\max }=0.5 \mathrm{~mm}$ are reached. However, further SEM tests were conducted on the machined surface, where results showed that in general the machined surface presented different types of defects, such as matrix tearing, micro-pits, grooves and scratches. It must be highlighted that these defects were more significant when the tool presented higher wear. Figure 14 shows an example of this result when increasing the tool wear. As observed, the severity of the defects increased at the final stage of the cutting process where the tool wear reached a value higher than $0.9 \mathrm{~mm}$, and as a consequence, tool flank wear, radial wear, chipping and breakage were very severe. Also, as the tool has lost its normal cutting ability, the cutting tool has torn the material rather than producing a clean cut of the Stellite developing pressing and matrix tearing on the machined surface; however, in some cases, the value of surface roughness decreased with the increase in tool wear (also shown in Fig. 13), and this phenomenon is due to the pressing and extrusion effect of the over worn tool cutting edge against the material removed. See Fig. 14(b) and (c). 
Table 12 ANOVA data for the surface roughness

\begin{tabular}{lcccccc}
\hline Factor & Degrees of freedom & Sum of squares (SDQ) & Variance & Test $\boldsymbol{F}$ & $\boldsymbol{F}, \mathbf{5 \%}$ & Percentage of contribution \\
\hline A $(V, \mathrm{~m} / \mathrm{min})$ & 2 & 111.96 & 55.98 & 46.57 & 3.98 & 38.29 \\
B $\left(v_{f}, \mathrm{~mm} / \mathrm{min}\right)$ & 2 & 166.29 & 83.14 & 69.17 & 3.98 & 36.88 \\
C $\left(a_{p}, \mathrm{~mm}\right)$ & 2 & 0.90 & 0.45 & 0.37 & 3.98 & 0.31 \\
Error & 11 & 13.22 & 1.20 & & 4.52 \\
Total & 17 & 292.38 & 36.54 & & & 100 \\
\hline
\end{tabular}

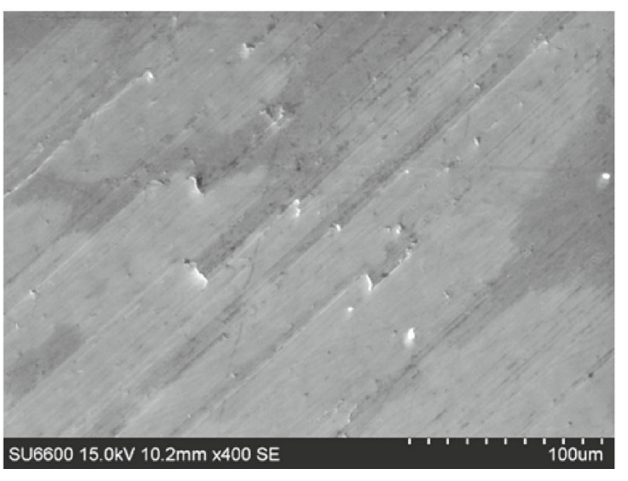

(a)

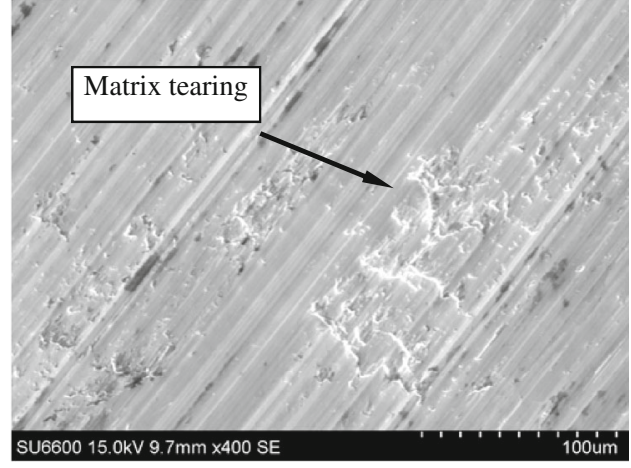

(b)

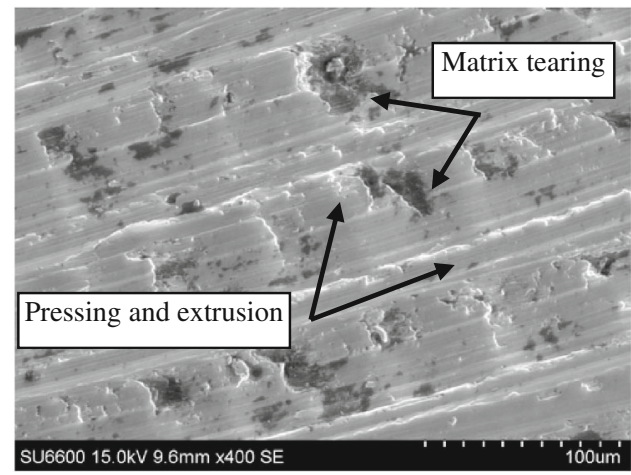

(c)

Fig. 14 Detail of the machined surface at different tool wear stages when cutting at $30 \mathrm{~m} / \mathrm{min}, 25 \mathrm{~mm} / \mathrm{min}$ and $1.5 \mathrm{~mm}$ as axial depth of cut (Trial 4) a) Cutting time $=2.8 \mathrm{~min}, \mathrm{VBmax}=0.19 \mathrm{~mm} \mathrm{Ra}=0.34 \mu \mathrm{m}, \mathrm{Rz}=1.92 \mu \mathrm{m}$, (b) cutting time $=5.6 \mathrm{~min}, \mathrm{VBmax}=0.66 \mathrm{~mm} \mathrm{Ra}=0.45$ $\mu \mathrm{m}, \mathrm{Rz}=2.31 \mu \mathrm{m}$, and (c) cutting time $=16 \mathrm{~min}, \mathrm{VBmax}=0.97 \mathrm{~mm}, \mathrm{Ra}=0.38 \mu \mathrm{m}, \mathrm{Rz}=2.01 \mu \mathrm{m}$

\subsection{The Effect of Tool Wear on the Deformation Layer}

The deformation layer of the machined surface was analyzed at the first stage of the cutting process $(L=70 \mathrm{~mm})$ and at the end of the cutting process $(L=400 \mathrm{~mm})$. Figure 15 shows an example of the details of the deformed layer when cutting under specific cutting conditions. For all of the machined Stellite samples, the distance from the machined surface toward the Stellite-steel interface is in the range of $1.8-3.8 \mathrm{~mm}$.

As observed from Fig. 15, no grain fracture or refinement was revealed during the cutting process; however, a larger grain elongation was present, especially when the tool reached a high value of wear (Fig. 15b). It was also observed that the cutting parameters had a significant effect on the depth of the deformation layer. This is explained in Fig. 16, where the depth of deformation layer increased almost $100 \%$, from 79 to $154 \mu \mathrm{m}$, corresponding to Trial 1 (low combination of cutting parameters, Fig. 16a) and Trial 9 (high combination of cutting parameters, Fig. 16b), respectively. It was also observed that in general when using a low combination of cutting parameter, the depth of deformation layer slightly increased with an increase in tool wear, as reported in Fig. 16(a); however, a defined pattern could not be established when using a higher combination of cutting parameters (Trial 9, Fig. 16b). This result is probably due to a tempering effect from the cutting heat (Ref 23) which has a softening effect on the machined surface/subsurface when the value of tool wear is large enough. Figure 15(c) shows a detail of the machined surface where a change in color was observed due to cutting heat (area inside dash contour lines).

\subsection{Effect of Cutting Parameters and Tool Wear on the Residual Stress}

The influence of the cutting parameters on the residual stress is shown in Fig. 17. As observed, compressive residual stresses 


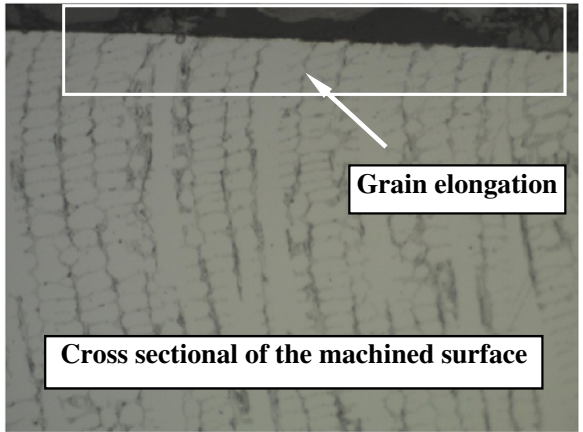

(a)

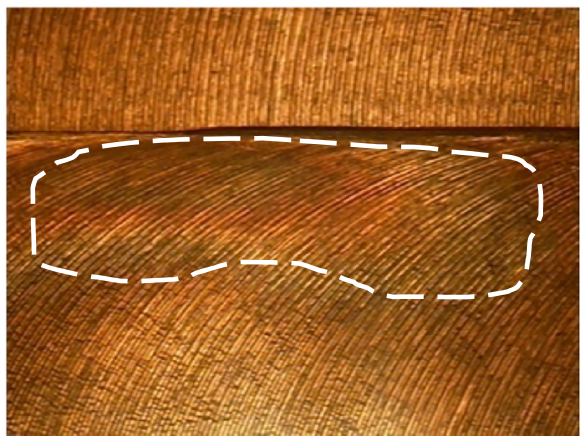

(c)

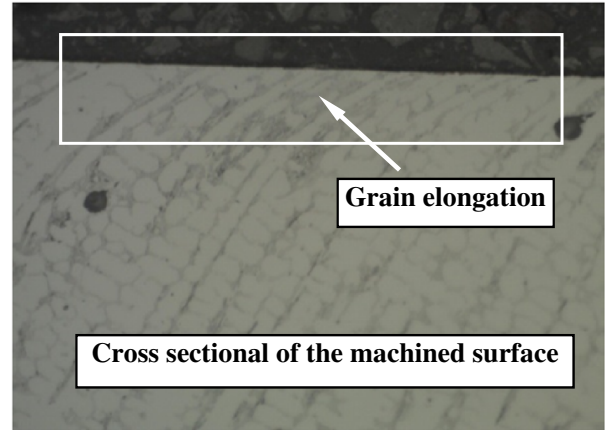

(b)

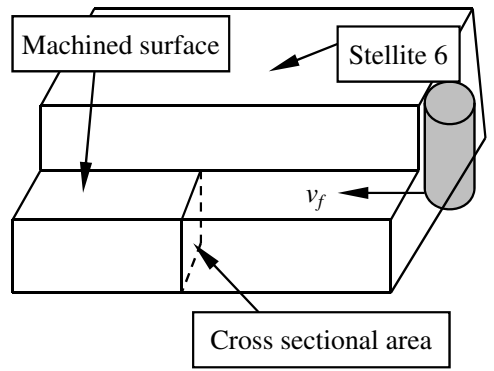

(d)

Fig. 15 Detail of the study of the deformation layer and machined surface for Trial $9(40 \mathrm{~m} / \mathrm{min}, 150 \mathrm{~mm} / \mathrm{min}$ and axial depth of cut $0.5 \mathrm{~mm})$ (a) $\operatorname{VBmax}=0.26 \mathrm{~mm}(\mathrm{~L}=70 \mathrm{~mm})$, (b) VBmax $=1.0 \mathrm{~mm}(\mathrm{~L}=400 \mathrm{~mm})$, (c) machined surface $(\mathrm{VBmax}=1.0 \mathrm{~mm})$ and $(\mathrm{d})$ schematic drawing of the cross-sectional area

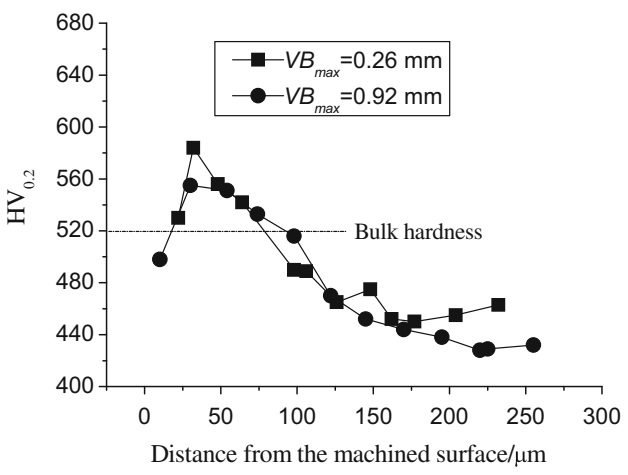

(a)

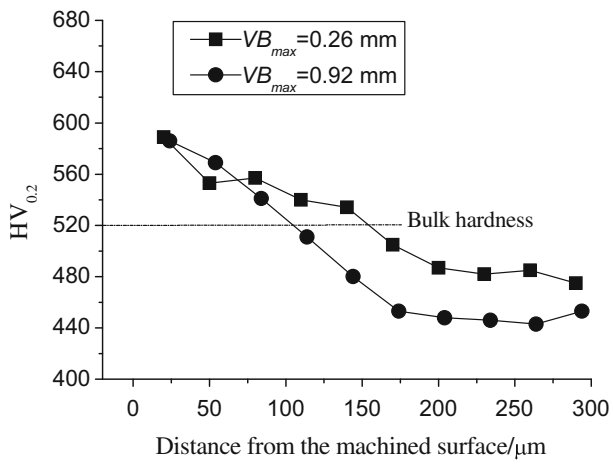

(b)

Fig. 16 Depth of deformation layer for trials 1 and 9 after reaching different values of tool wear (a) Trial 1 and (b) Trial 9

were generally found to be present in the Stellite layer before conducting the milling process (un-machined condition). These compressive stresses were probably introduced in the Stellite coating as a consequence of a grinding process that was conducted in order to smooth the surface after the welding process (it must be highlighted that samples were provided under this condition). As observed from Fig. 17 in general, a decrease of $65-90 \%$ in the compressive stresses was obtained after cutting a length of $70 \mathrm{~mm}$ at low speeds $(\leq 30 \mathrm{~m} / \mathrm{min}$, Fig. 17(a) and (b) machined surface). However, when cutting conditions were increased (cutting speed $>30 \mathrm{~m} / \mathrm{min}$ ), such as for Trial 9 (Fig. 17c), the residual stresses changed 100\% from compressive to tensile when cutting the same length of cut ( $L=70 \mathrm{~mm}$ ). This result is probably attributed to the high cutting temperature involved in the process due to the dry cutting environment that was used and due to the low thermal diffusivity of the Stellite 6 (14.82 W/m) (Ref 23).

Figure 18 shows an example on how the cutting time and, as a consequence, the tool wear affect the residual stresses. When analyzing Fig. 18, it is observed that the value and the depth of the compressive residual stresses significantly decreased when cutting for a short period of time $(t=1.8 \mathrm{~min})$. As observed, the stresses decreased after conducting the milling process in $54 \%$ (from -550 to $-300 \mathrm{MPa}$ ) in $Y$ direction and in $25 \%$ 


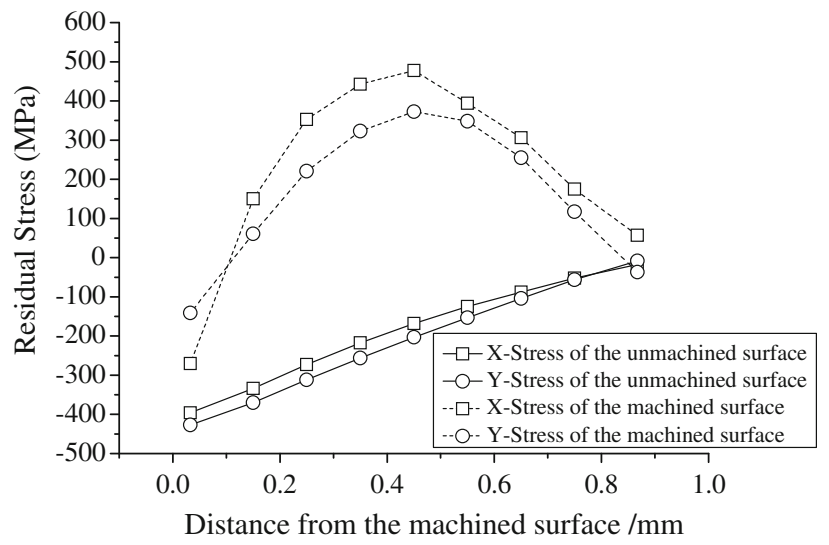

(a)

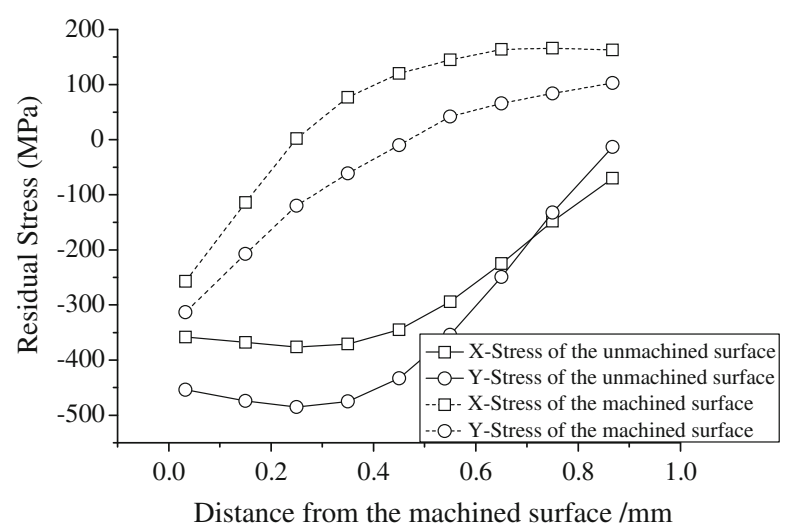

(b)

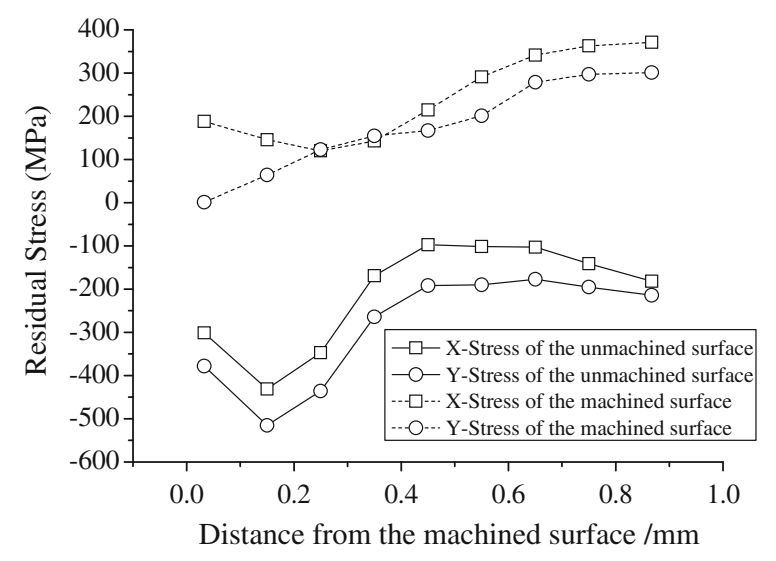

(c)

Fig. 17 Residual stresses on the machined surface when milling under different cutting conditions. (a) Trial $1(20 \mathrm{~m} / \mathrm{min}, 25 \mathrm{~mm} / \mathrm{min}$, $0.5 \mathrm{~mm})$, (b) Trial $5(30 \mathrm{~m} / \mathrm{min}, 75 \mathrm{~mm} / \mathrm{min}, 0.5 \mathrm{~mm})$ and (c) Trial $9(40 \mathrm{~m} / \mathrm{min}, 150 \mathrm{~mm} / \mathrm{min}, 0.5 \mathrm{~mm})$

(from -470 to $-120 \mathrm{MPa}$ ) in $X$ direction. Figure 18 also shows how the residual stresses changed completely from compression to tension after machining for a period of $5.3 \mathrm{~min}$ where the tool wear increased $80 \%$ (from 0.69 to $1.24 \mathrm{~mm}$ ). As previously mentioned, these results are attributed to the high cutting temperature involved in the process due to the fact that a

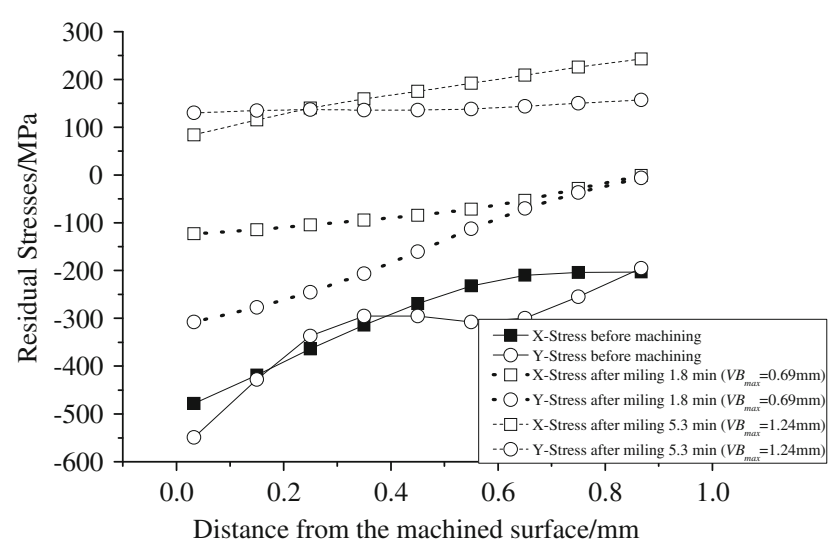

Fig. 18 Influence of residual stresses when increasing the cutting time

dry cutting environment was used and due to the low thermal diffusivity of the Stellite 6 (14.82 W/m) (Ref 23).

\subsection{Influence of Cutting Parameters on the Chip Formation and Morphology}

Figure 19 shows few examples of the chips collected after the machining process under different cutting conditions. Figure 19(a) highlights that the flow type and the saw-toothed type morphology can be formed in the same chip at the same time. The saw-toothed or serrated shape chip is similar to the chip formed when machining, for example, nickel-based hardfacing layers (Ref 24), in which the formation mechanism is partial fracture due to the existence of precipitates and carbides in the matrix. As seen in Fig. 1, the typical microstructure of the Stellite 6 alloy consists of $\alpha$-Co (Corich matrix) dendrites surrounded by lamellar mixture of the Co-rich phase and carbide phase. During the machining process, these carbides and the inclusions in the Stellite coating are the sources of crack initiation; therefore, in most of the cases, micro-crack initiation and its propagation are the main mechanism of chip formation for the saw-toothed type morphology. As shown in Fig. 19(b), the cracks highlighted in the image were mostly generated near the Co-rich phases and carbide phases (Stellite coating, Fig. 1). It was also observed that the material deformation inside the chip is non-uniform and the underside of the chip experienced obvious deformation, while the material in the saw tooth only experienced a slight deformation (Fig. 19b). Due to the dynamic behavior of the cracks, the shape and size of the saw tooth were quite different, as shown in Fig. 19(c). Adiabatic shear is another mechanism of chip formation for the saw-toothed type, and as shown in Fig. 19(d), an adiabatic shear zone was found when using higher values of cutting speed and feed rate $(40 \mathrm{~m} / \mathrm{min}, 75 \mathrm{~mm} /$ min). As observed, in the adiabatic shear zone, the grain suffered from severe deformation and the shear cracks were generally formed near the adiabatic shear zone. It is worth emphasizing that, at present, the authors are not aware of studies related to chip formation mechanisms when machining cobalt or Stellite alloys; therefore, this also makes a new and relevant contribution in the area related to the dynamic behavior of the cracks and adiabatic shear behavior mechanisms of chip formation when machining this alloy. 


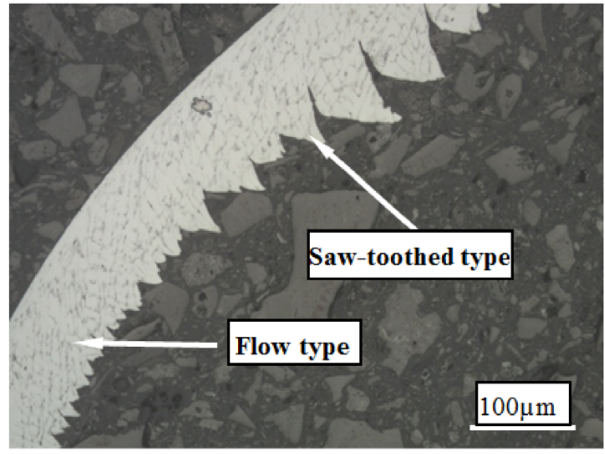

(a)

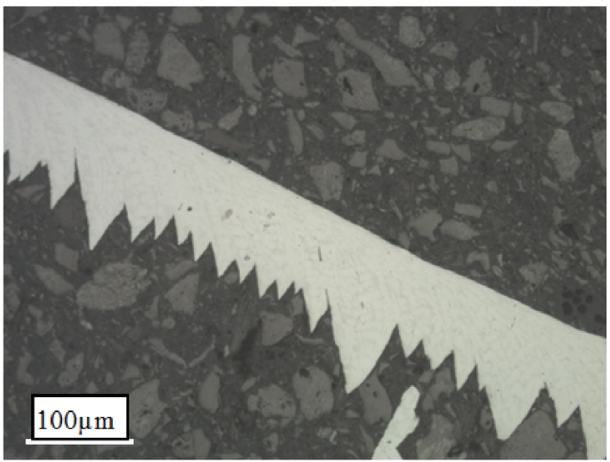

(c)

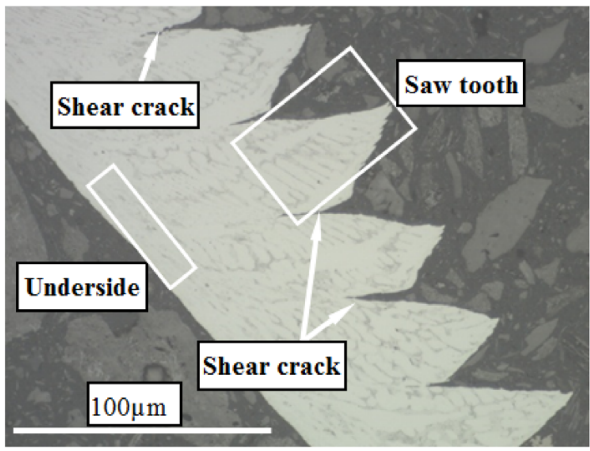

(b)

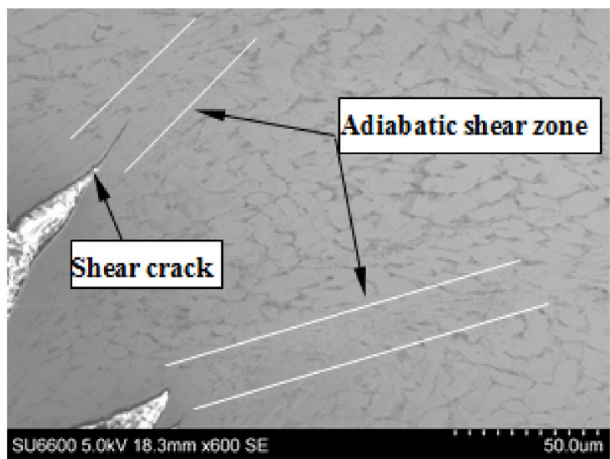

(d)

Fig. 19 Chip morphology and formation mechanisms obtained under different cutting conditions (a) chip for Trial $2(20 \mathrm{~m} / \mathrm{min}, 75 \mathrm{~mm} / \mathrm{min}$, ap = $1.0 \mathrm{~mm})$, (b) chip for Trial $6(600 \mathrm{~m} / \mathrm{min}, 150 \mathrm{~mm} / \mathrm{min}$, ap = $1.0 \mathrm{~mm})$, (c) chip for Trial $5(30 \mathrm{~m} / \mathrm{min}, 75 \mathrm{~mm} / \mathrm{min}$, ap $=0.5 \mathrm{~mm})$ and $(\mathrm{d})$ chip for Trial $8(40 \mathrm{~m} / \mathrm{min}, 75 \mathrm{~mm} / \mathrm{min}$, ap $=1.5 \mathrm{~mm})$

\section{Conclusions}

- Milling of weld-deposited Stellite 6 under selected cutting conditions has shown that the feed rate is the main factor affecting the tool wear and the surface roughness with a contribution of 83 and $57 \%$, respectively.

- The main tool wear mechanisms present in the process were abrasion at low cutting speed $(\leq 30 \mathrm{~m} / \mathrm{min})$ and coating peeling, chipping, diffusion and breakage for higher cutting speeds $(>30 \mathrm{~m} / \mathrm{min})$. These later tool wear mechanisms were responsible for the tearing of the material removed producing pressing and matrix tearing on the machined surface affecting its roughness.

- The optimum combination of cutting parameters to obtain a minimum roughness and tool wear is $40 \mathrm{~m} / \mathrm{min}, 25 \mathrm{~mm} /$ min and $0.5 \mathrm{~mm}$ for the axial depth of cut.

- The cutting parameters had a greater influence on the deformation layer compared to the tool wear; however, an increase in this last one produced elongation of the grains near the machined surface. Finally, when the cutting time was increased ( $>5 \mathrm{~min}$ ), the original compressive stresses were converted $100 \%$ into tensile stresses.

- The depth of deformation layer ranged from 75 to $150 \mu \mathrm{m}$ where a softening layer was generated on the machined surfaces/subsurfaces for most of the cutting tests but vanished when cutting speed and feed rate increased to $40 \mathrm{~m} / \mathrm{min}$ and $150 \mathrm{~mm} / \mathrm{min}$.

- The chips presented a flow type and saw-toothed type morphology, and in most of the cases, micro-crack initiation and its propagation were the main mechanisms of chip formation for the saw-toothed type morphology. The adiabatic shear zone was found when using higher feed rate $(75 \mathrm{~mm} / \mathrm{min})$ and cutting speed $(40 \mathrm{~m} / \mathrm{min})$.

\section{Acknowledgements}

This project was supported by the National Natural Science Foundation of China (51275227), Nanjing Science and Technology Development Plan (201306024), the Qinglan Project of Jiangsu Province (2014) and the Department of Mechanical and Aerospace Engineering of the University of Strathclyde. 


\section{Open Access}

This article is distributed under the terms of the Creative Commons Attribution 4.0 International License (http://creativecommons. org/licenses/by/4.0/), which permits unrestricted use, distribution, and reproduction in any medium, provided you give appropriate credit to the original author(s) and the source, provide a link to the Creative Commons license, and indicate if changes were made.

\section{References}

1. J. Sato, T. Omori, K. Oikawa, I. Ohnuma, R. Kainuma, and K. Ishida, Cobalt-Base High-Temperature Alloys, AAAS/Science, 2006, 312(5770), p 90-91

2. V. Kuzucu, M. Ceylan, H. Celik, and I. Aksoy, An Investigation of Stellite-6 Alloy Containing $5.0 \mathrm{wt} \%$ Silicon, J. Mater. Process. Technol., 1998, 79, p 47-51

3. M. Benghersallah, L. Boulanouar, G.L. Coz, A. Devillez, and D. Dudzinski, Dry High Speed Milling of Cobalt-Base Hard Facing Superalloy, Mechanika, 2012, 18(5), p 591-599

4. H. Danny, W. Rafael, H. Thomas, T. Stefan, Milling of cast material and PT-hard-facing layers of the cobalt-base-alloy stellite 12. Annals of DAAAM for 2011 and Proceedings of the 22nd International DAAAM Symposium, 2011, vol. 22, p 949-950

5. C. Lahiff, S. Gordon, and P. Phelan, PCBN Tool Wear Modes and Mechanisms in Finish Hard Turning, Robot. Comput. Integr. Manuf., 2007, 23, p 638-644

6. W. Ji, X.L. Liu, H.Y. Li, H.Y. You, and M.C. Fan, Research of PCBN Tool Wear Mechanism in Turning Ni-based Superalloy, Adv. Mater. Res., 2013, 820, p 185-189

7. E. Bagci and S. Ayku, A Study of Taguchi Optimization Method for Identifying Optimum Surface Roughness in CNC Face Milling of Cobalt-Based Alloy (stellite 6), Int. J. Adv. Manuf. Technol., 2006, 29, p 940-947

8. M. Benghersallah, L. Boulanouar, G.L. Coz, A. Devillez, and D. Dudzinski, Machinability of Stellite 6 Hardfacing, EPJ Web Conf., 2010, 6, p 1-8
9. S. Aykut, E. Bagci, A. Kentli, and O. Yazicioglu, Experimental Observation of Tool Wear, Cutting Forces and Chip Morphology in Face Milling of Cobalt Based Super-Alloy with Physical Vapor Deposition Coated and Uncoated Tool, Mater. Des., 2007, 28, p 1880-1888

10. S. Ozturk, Machinability of Stellite-6 Coatings with Ceramic Inserts and Tungsten Carbide Tools, Arab. J. Sci. Eng., 2014, 39, p 7375-7383

11. H. Shao, L. Li, L.J. Liu, and S.Z. Zhang, Study on Machinability of a Stellite Alloy with Uncoated and Coated Carbide Tools in Turning, $J$. Manuf. Process., 2013, 15, p 673-681

12. ASME B46.1: Surface Texture (Surface Roughness, Waviness, and Lay), 2009

13. ISO 8688-2: Tool Life Testing in Milling_Part 2: End Milling, 1989

14. ISO 4499-2: Hard Metals-Metallographic Determination of Microstructure, Part 2: Measurement of WC Grain Size, 2008

15. ISO 21608: Corrosion of Metals and Alloys-Test Method for Isothermal-Exposure Oxidation Testing Under High-temperature Corrosion Conditions for Metallic Materials, 2012

16. ISO 6507-1: Metallic Materials-Vickers Hardness Test. Part 1. Test method, 2010

17. G.S. Schajer, Non-uniform Residual Stress Measurements by the Hole Drilling Method, Strain, 1992, 28, p 19-22

18. G.S. Schajer, Measurement of Non-Uniform Residual Stresses Using the Hole-Drilling Method. Part I-Stress Calculation Procedures, Trans. ASME, 1988, 110, p 338-343

19. ASTM E837-08: Standard Test Method for Determining Residual Stresses by the Hole-Drilling Strain-Gage Method, 2009

20. C. Robert, J. Adam, P. Jana, C. Lenka, S. Marek, and K. Jiri, Hard Machinable Machining of Cobalt Superalloys, Sci. Proc., 2012, 20, p $42-47$

21. Durul Ulutan and Tugrul Ozel, Machining Induced Surface Integrity in Titanium and Nickel Alloys: A Review, Int. J. Mach. Tools Manuf., 2011, 51, p 250-280

22. M.S. Hasan, A.M. Mazid, and R.E. Clegg, Optimization of the Machining of Stellite 6 PTA Hardfacing Using Surface Roughness, Key Eng. Mater, 2010, 443, p 227-231

23. F. Rosalbino and G. Scavino, Corrosion Behaviour Assessment of Cast and HIPed Stellite 6 Alloy in Achloride-Containing Environment, Electrochim. Acta, 2013, 111, p 656-662D

24. M. Mansori and M. Nouari, Dry Machinability of Nickel-Based WeldHardfacing Layers for Hot Tooling, Int. J. Mach. Tools Manuf., 2007, 47, p 1715-1727 